researchers at Leiden University in the Netherlands ${ }^{1}$. Yet the swim test's track record is mixed. It has accurately predicted whether various SSRIs are effective treatments for depression, but yields inconsistent results when used with other types of antidepressant.

Concerns about the forced-swim test's accuracy have prompted major drug companies such as Roche, Janssen and AbbVie to abandon the procedure in recent years.

Many researchers feel obligated to use the test, says Ron de Kloet, a neuroendocrinologist at Leiden University Medical Center and a coauthor of the 2015 study. "People get their grants based on this test, they write papers based on the test, they make careers," he says. "Most of them will admit that the tests are not showing what they are supposed to do."

Todd Gould, a neurobiologist at the University of Maryland School of Medicine in Baltimore, acknowledges the test's poor track record, but says the procedure has proved useful for his research into whether the 'party drug' ketamine and related substances are effective antidepressants ${ }^{2}$. Gould finds it ironic that an animal-rights group is attacking the NIMH, because Gordon and several of his predecessors have been outspoken advocates of developing objective biological measures of depression and other mental-health disorders. In practical terms, that has meant looking for alternatives to many animal tests. Gould says that NIMH staff have tended to push back against his proposals that have included forced-swim tests.

The agency told Nature that it requires grant applicants to supply written justification for the use of animals in research, and that it "evaluates these descriptions very rigorously".

Emily Trunnell, a research associate with PETA's Laboratory Investigations Department

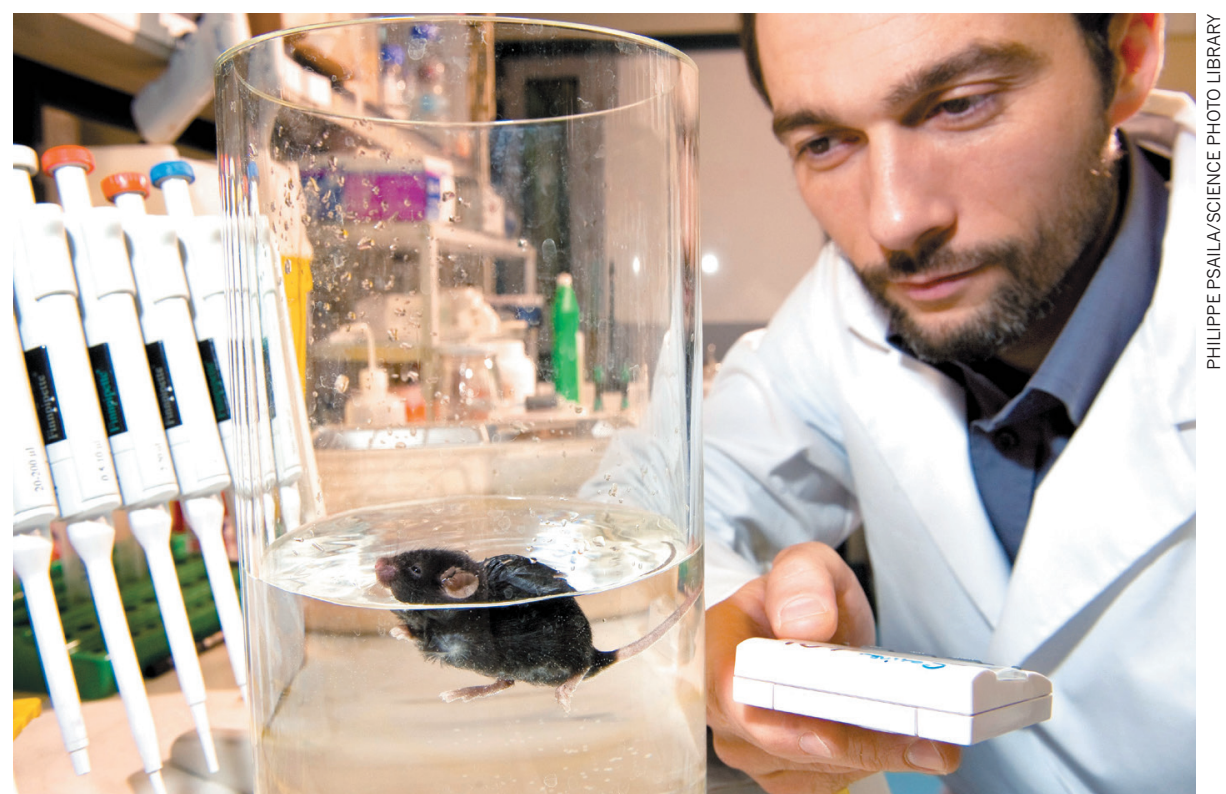

Scientists gauge a mouse's mental health by measuring the time it takes to stop swimming.

in Norfolk, Virginia, says that the group decided to target the NIMH because of the agency's prominence in mental-health research. "If NIMH took a stand, it would set a strong precedent," she says.

She argues that emerging technologies, such as 'mini-brains' grown from human stem cells, could eliminate the need to use rodents in depression studies. Researchers are already using these clumps of human tissue to study the genetics and brain wiring that underlie various mental-health disorders ${ }^{3}$.

But some scientists say that the best replacement for the forced-swim test might be more sophisticated tests that involve rodents or other animals. Robbins says that one approach could include developing animal tests that accurately measure specific symptoms, such as lack of interest in a favourite food.

And Nestler says that modelling individual signs of depression might produce better data than do attempts to mimic the full complexity of the human disorder in animals. The symptoms and underlying genetics of depression seem to vary widely between people, and the same treatments don't work for everyone.

"We know human depression is not one disease," he says.

1. Molendijk, M. L. \& de Kloet, E. R. Psychoneuroendocrinology 62, 389-391 (2015)

2. Zanos, P. et al. eNeuro 4, ENEURO.0285-16.2017 (2017).

3. Wang, M., Zhang, L. \& Gage, F. H. Protein Cell https://doi.org/10.1007/s13238-019-0638-8 (2019).

\title{
EU chief makes bold climate pledges
}

\author{
Newly elected European Commission president Ursula \\ von der Leyen plans to strengthen carbon-cutting goals.
}

\section{BY QUIRIN SCHIERMEIER}

$\mathrm{G}$ erman defence minister Ursula von der Leyen was elected as the next president of the European Commission on 16 July - and she has put climate change at the top of her agenda. Von der Leyen was narrowly voted in by Members of the European Parliament (MEPs), and will be the first woman to take the top job in Brussels, where she will lead the European Union's executive branch and guide its policy agenda. She takes office in November. In a speech to parliament before her election, von der Leyen said that she intends to make climate and the environment priorities in all policy areas. She pledged to strengthen the EU's short-term goal on greenhouse-gas emissions from a $40 \%$ reduction by 2030 to at least a $50 \%$ cut, relative to 1990 levels. The EU will also take the lead in international climate negotiations, and will encourage other major economies to increase their ambitions by 2021, she said.

From a scientific perspective, the more ambitious carbon-reduction target is a crucial step, says Ottmar Edenhofer, director of the Potsdam Institute for Climate Impact Research in Germany. "Now she will have to deliver on those promises."

Von der Leyen is also set to announce a 'Green Deal for Europe' in her first 100 days in office, which would include a law to make Europe carbon neutral by 2050. "I want Europe to become the first climate-neutral continent in the world," she said.

The proposed deal, outlined in a political agenda she released last week, includes a biodiversity strategy for Europe, an extended emissions-trading system and a tax to avoid carbon 'leakage' - when companies transfer the production of goods to countries with more relaxed emission limits. She also pledged to $>$ 
- unlock $€ 1$ trillion (US\$1.1 trillion) over the next decade for climate investment.

The proposed policies would make Europe a leader in international climate-protection efforts, says Claudia Kemfert, a climate and energy policy specialist at the German Institute for Economic Research in Berlin. "The Green Deal is groundbreaking, and will create huge economic opportunities by opening up new markets and avoiding climate damage," she says.

But von der Leyen's climate proposals were met with criticism from some - including the parliament's alliance of Green Party lawmakers, who voted against her. "We were elected on an agenda for change and we did not hear enough on our key demands, namely, on concrete proposals to avert climate breakdown," said alliance co-leader Ska Keller.

The new president will need to win the backing of EU nations - strengthening climate targets is something that EU member states must decide by consensus, says Oliver Geden, a policy researcher at the German Institute for International and Security Affairs in Berlin.

Von der Leyen will succeed Luxembourg politician Jean-Claude Juncker, who has been commission president since 2014. Before taking office, she will select a cabinet of commissioners, including a successor to outgoing research commissioner Carlos Moedas.

The details of the EU's next multibillioneuro research-funding programme, Horizon Europe, will be finalized by the commission and parliament before the end of this year. Horizon Europe will include a strong focus on aspects of climate change.

Additional reporting by Nisha Gaind.

\section{Mystery deepens over speed of Universe's expansion}

\section{Technique fails to resolve disagreement over how fast cosmos is expanding - for now.}

\section{BY DAVIDE CASTELVECCHI}

$\mathrm{F}$ or much of this decade, the two most 1 precise gauges of the Universe's rate of expansion have been in glaring disagreement. Now, a highly anticipated independent technique that cosmologists hoped would solve the conundrum is instead adding to the confusion.

In an analysis unveiled on 16 July and due to appear in the Astrophysical Journal, a team led by astronomer Wendy Freedman at the University of Chicago in Illinois presented a technique that measures the expansion using red-giant stars. It had promised to replace a method that astronomers have been using for more than a century - but for now, the measurement has failed to resolve the dispute because it falls halfway between the two contentious values.

"The Universe is just messing with us at this point, right?" tweeted one astrophysicist about the paper.

"Right now, we're trying to understand how it all fits together," Freedman told Nature. If the cosmic-speed discrepancy is not resolved, some of the basic theories that cosmologists use to interpret their data - such as assumptions about the nature of dark matter - could be wrong. "Fundamental physics hangs in the balance," Freedman says.

\section{COSMIC SPEEDOMETER}

US astronomer Edwin Hubble and others discovered in the 1920s that the Universe is expanding. They showed that most galaxies are receding from the Milky Way — and the farther away they are, the faster they are receding. The roughly steady ratio between speed and distance became known as the Hubble

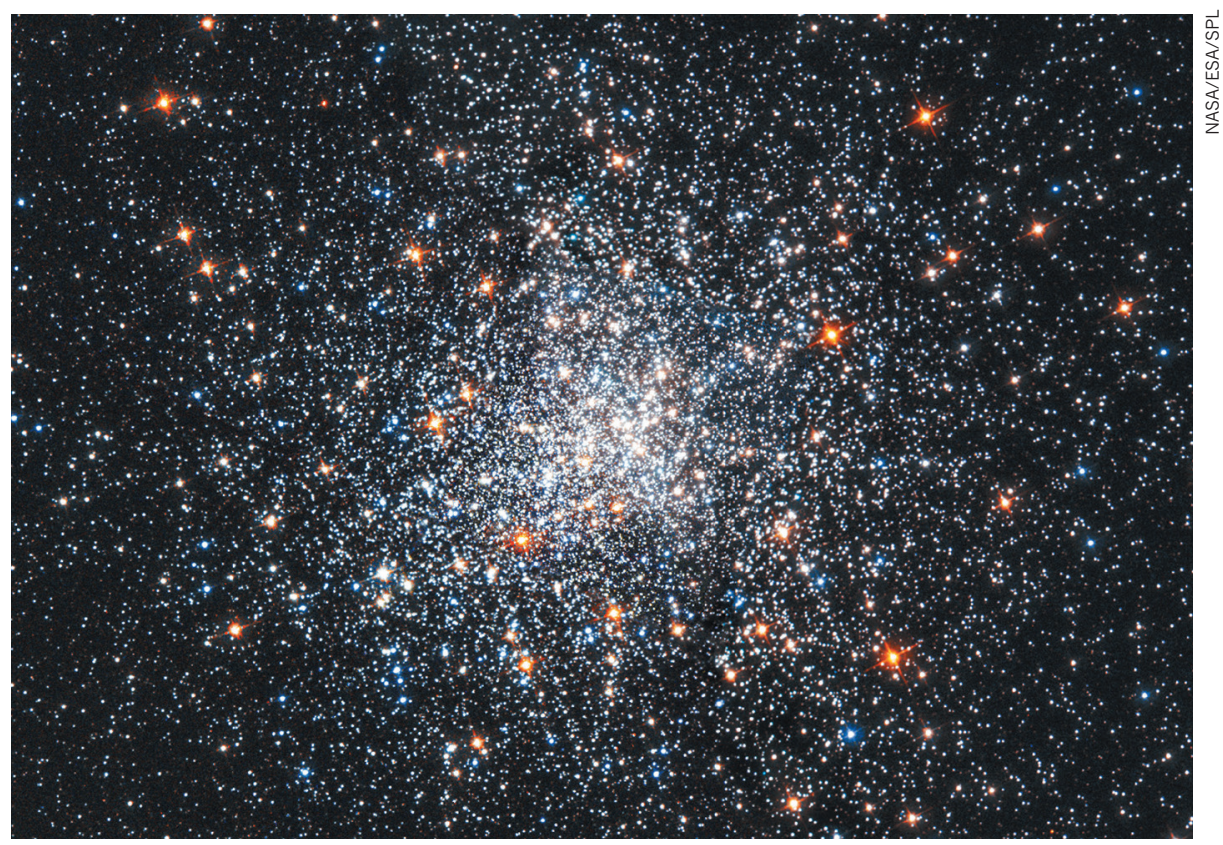

Red-giant stars are the focus of a new method that measures the Universe's rate of expansion.

constant. For each additional megaparsec (around 3.26 million light years) of distance, Hubble found that galaxies receded 500 kilometres per second faster - so the Hubble constant was 500, in units of kilometres per second per megaparsec.

Over the decades, astronomers revised the estimate down substantially as measurement techniques improved. Fittingly, Freedman pioneered the use of the Hubble Space Telescope in the 1990s to measure the Hubble constant, and calculated a value of around 72 with an error margin of around $10 \%$. A team led by Nobel laureate Adam Riess at Johns Hopkins
University in Baltimore, Maryland, has made the most precise measurements so far, and the group's latest value is 74, with an error margin of just $1.91 \%$ (A. G. Riess. et al. Preprint at https://arxiv.org/abs/1903.07603; 2019).

But a separate effort in the past decade has thrown a spanner in the works. Scientists with the European Space Agency's Planck mission mapped the relic radiation of the Big Bang, called the cosmic microwave background, and used it to calculate the Universe's basic properties. Using standard theoretical assumptions about the cosmos, they calculated the Hubble constant as 67.8 . 